\title{
A Review on Electrochemical Properties of Choline Chloride Based Eutectic Solvent in Mineral Processing
}

\author{
*11OBETEN, ME; UGI, BU; ALOBI, NO \\ Department of Chemical Sciences, Cross River University of Technology, P. M. B. 1123 \\ Calabar - Cross River State, Nigeria.
}

\begin{abstract}
Our review highlights the most recent developments in ionic liquid (IL) chemistry where the "well-known" description of IL properties sometimes proves to be inaccurate. However, in the authors' opinion, all these new research developments concerning ionic liquid properties serve to update knowledge on the typical physical and chemical properties of ILs, which is significant to both theoretical research and industrial applications. Therefore, rather than attempting to give a comprehensive overview of ionic liquid chemistry, the paper presents an opportunity to understand deep eutectic solvents (DES) through a more complete and accurate view. (C) JASEM

https://dx.doi.org/10.4314/jasem.v21i5.29
\end{abstract}

Keywords: Eutectic; Solvents; Electrochemistry; Ionic Liquids; purification; Ethylene glycol.

Since environmental pollution caused by chemical and energy industries has increased for several decades, there is high expectation from scientists and engineers to design sustainable chemical processes, to generate less harmful materials and more environmentally friendly sources of energy production. To be qualified as a green medium, these solvents must meet different standards such as availability, recyclability, non-toxicity, biodegradability, flammability, and low price among others. Up to now, the number of available green solvents are rather limited.

The search for the right solvent is essential in chemistry, since it constitutes around $95 \%$ of the total volume of chemicals used in a process (Qinghua et al., 2012). Solvents present numerous environmental, health and safety challenges including human and eco-toxicity issues, process safety hazards as well as waste management issues (Smith, 2004). Following the principles of green chemistry, most of the organic solvents do not fulfil the requirements for their use in green technology, since they have an in-built toxicity, environmental impact, and a high volatility. In the last decades, several efforts have been made to replace organic solvents.

This approach comprises the application of easy recyclable systems such as supercritical $\mathrm{CO}_{2}\left(\mathrm{scCO}_{2}\right)$ or the non -volatile systems such as ionic liquids (ILs), deep eutectic solvents (DESs) and low-melting mixtures (LMMs) (Qinghua et al., 2012). Abbott et al., in (2007), defined DESs using the general formula $\mathrm{R}_{1} \mathrm{R}_{2} \mathrm{R}_{3} \mathrm{R}_{4} \mathrm{~N}^{+} \mathrm{X} \square$. Y $\square$

Type I DES Y $=\mathrm{MCl}_{\mathrm{x}}, \mathrm{M}=\mathrm{Zn}, \mathrm{Sn}, \mathrm{Fe}, \mathrm{Al}, \mathrm{Ga}$ Type II DES Y = MClx.yH $\mathrm{H}_{2} \mathrm{O}, \mathrm{M}=\mathrm{Cr}, \mathrm{Co}, \mathrm{Cu}, \mathrm{Ni}$, Fe

Type III DES $\mathrm{Y}=\mathrm{R}_{5} \mathrm{Z}$ with $\mathrm{Z}=-\mathrm{CONH}_{2},-\mathrm{COOH}$, $-\mathrm{OH}$

The same group also defined a fourth type of DES which is composed of metal chlorides (e.g. $\mathrm{ZnCl}_{2}$ ) mixed with different hydrogen bond donors (HBDs) such as urea, ethylene glycol, acetamide or hexanediol (type IV DES).

Owing to its low cost, biodegradability and low toxicity, $\mathrm{ChCl}$ was widely used as an organic salt to produce eutectic mixtures generally with cheap and safe HBDs such as urea, glycerol, carbohydratederived polyols or renewably sourced carboxylic acids (Abbott et al., 2009).

Deep eutectic solvents are considered a new class of ionic liquids sharing many of their properties but coming in at lower cost. They are mixtures of different substances proportions that melt and freeze at lower temperature than those of individual components or mixtures of the components in other proportions (Abbott et al., 2009). The first major problem encountered is that the majority of ILs is prohibitively expensive and likely to remain so in the foreseeable future. This precludes their use in anything other than niche applications. For this reason, the subject of this review is an IL based on the combination of ethylene glycol and choline chloride, known as ethaline. Ethaline exhibits similar physical and chemical properties to ILs. It is stable under ambient conditions, cheap and biodegradable. It is the most conductive and least viscous member of a group of deep eutectic solvents (DES) (Abbott et al., 2009).

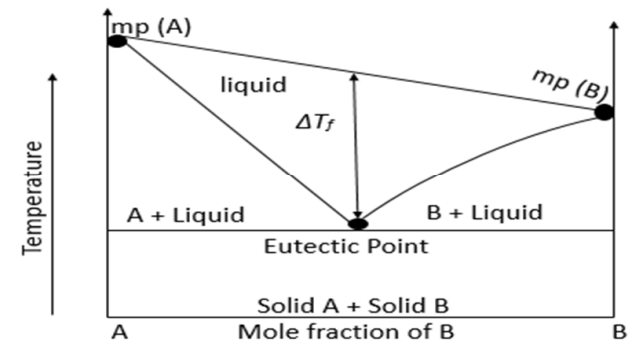


Fig.1. Schematic representation of a eutectic point on a twocomponent phase diagram (MP = melting point).

This property is a consequence of the hydrogen bonding between the components. Deep eutectic solvents are non-volatile, biodegradable and do not react with water. Although, DES have not been extensively used in metal extraction, it was found by Abbott et al., that eutectic solvents formed between quaternary ammonium halide and a hydrogen bond donor such as alcohol have advantage for metal extraction and electrowinning of metals from their ores (Abbott et al., 2014). However, DESs have been employed as alternative media for metals that are traditionally difficult to plate or involve environmentally hazardous processes (Free, 2003). DESs have the potential to offer a viable alternative to existing technologies. As mentioned before, eutectic systems are already used in many fields. The properties of a DES regarding its biodegradability and biocompatibility depend solely on the substances used. Therefore, natural-based DESs can be constituted using primary metabolites, namely, organic salts, amino acids, or choline derivatives (Dai, 2013). It's evident that these DESs fully fulfil the green chemistry principles. Here, the electrochemical properties of choline chloride based eutectic solvent are reviewed.

Applications of Deep eutectic solvents (DESs): Deep eutectic solvents (DESs) are another type of solvents exhibiting similar physical properties with ionic liquids. DESs have been studied for their applicability in industry at lab level, such as for production and purification of biodiesel.

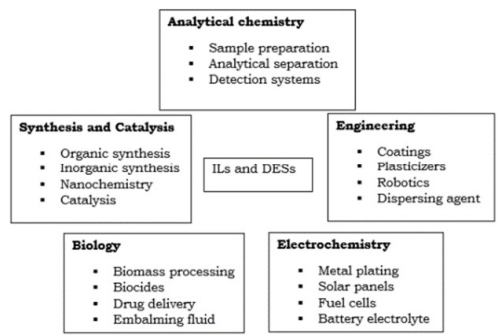

Fig.2: Fields of application of ionic liquids (ILs) and (DESs). Qinghua, et al., (2012)

A number of DES made up of different components, such as choline chloride, urea, and organic acids, have been reported especially considering their low environmental and economic impact, e.g. biodegradability, pharmaceutical acceptable toxicity, low cost, and simple preparation methods (Abbott et al., 2007).

They have been used as solvents to extract DNA and as media for enzymatic reactions. Because the solvent is conductive, ${ }^{16}$ it also has a potential application in electropolishing, and for metal cleaning prior to electroplating (Abbott et al., 2013).
Electrochemistry of deep eutectic solvents: The electrochemical potential window is an important indicator of electrochemical stability. This is because the redox couple of a given analyte in most reactions involving DES falls within this potential window. DESs have the ability to control the speciation of soluble metal salts due to the presence of high coordinating anions. In this potential range, the electrolyte neither reduced nor oxidised at an electrode surface. The potential window is one of the unique properties which may assist in the selection of DESs as an electrolyte and solvent in various spectroscopic and electrochemical applications. It should be noted that some DESs, e.g., DES TYPE 3 have a relatively high reduction limit. This allows the use of these DESs in many important electrochemical processes such as leaching and for extraction processes (Kareem, et al., 2010). The electrochemical potential window of the DESs (Ethaline) prepared in this work have been determined using cyclic voltammetry $(\mathrm{CV})$ at a scan rate of $10 \mathrm{mVs}^{-1}$ illustrated in Fig. 3. The electrochemical potential window lies approximately between 1.3 and -1 which imply that the potential window of Ethaline is around 2.3 volts on a $1 \mathrm{~mm} \mathrm{Pt}$ disc working electrode, against silver $(\mathrm{Ag})$ wire as reference electrode and platinum $(\mathrm{Pt})$ flag as counter electrode at room temperature.

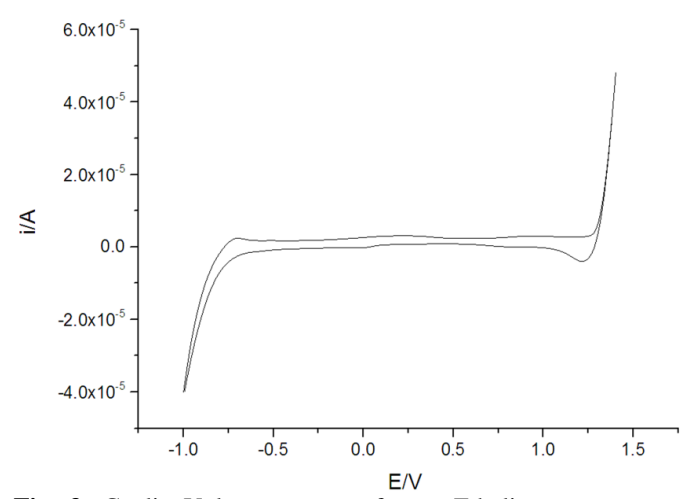

Fig. 3: Cyclic Voltammogram of pure Ethaline at scan rate 10 $\mathrm{mV} . \mathrm{s}^{-1}$

This behaviour has been further demonstrated by Abbott et al., (2014). in a recent paper on copper electrodeposition from a DES. In the results presented above, this is shown to be approximately true in the limiting case of extremely slow measurements. To make a better identification of the electrochemical steps involved in the redox processes, cyclic voltammetry was used to determine the kinetic parameters of these DES suggesting that the potential window is quite sufficient to deposit metals with high current efficiencies such as zinc, copper and nickel (Endres, et al., 2008).

Electrodeposition using deep eutectic solvents: Copper is easily deposited as an alloy with other metals, such as zinc. In the early 1960s and 1970s 
copper deposition was studied in chloroaluminate ionic liquids. In 1990, copper was found to be easily deposited using ionic liquids containing anions such as $\left[\mathrm{BF}_{4}\right]^{-},\left[\left(\mathrm{F}_{3} \mathrm{CSO}_{2}\right)_{2} \mathrm{~N}\right]^{-}$and $\left[\mathrm{Tf}_{2} \mathrm{~N}\right]^{-}$. The air and moisture stability of these systems made them easier to apply. Endres et al, 2008, studied copper deposition from (buthylmethyl pyrrolidinium) [BMP] $\left[\mathrm{Tf}_{2} \mathrm{~N}\right]$ - at different temperatures. However, this ionic liquid has limited solubility for copper compounds and copper cations had to be introduced into the liquid via anodic dissolution of a copper electrode. Recently, it has been shown that simple eutecticbased ionic liquids can be produced using the quaternary ammonium salts, $\mathrm{R}_{1} \mathrm{R}_{2} \mathrm{R}_{3} \mathrm{R}_{4} \mathrm{~N}^{+} \mathrm{X}^{-}$, complexed with hydrogen bond donors, such as acids, amides and alcohols (Abbott, et al., 2007). These so called deep eutectic solvents (DES) have been used for electropolishing, polymer synthesis, organic synthesis and metal oxide processing. The previous studies have concentrated on choline chloride as the quaternary ammonium salt, as it is environmentally friendly and is already used as a common constituent of various household and industrial products, such as detergents. The DESs formed with choline chloride and urea, or choline chloride and ethylene glycol, have successfully been employed for the electrodeposition of zinc, tin, and zinc-tin alloys (Abbott et al., 2008). This has also shown that the alloy is affected by the choice of hydrogen bond donor and that the electrochemistry of the components in solution, as well as the morphology of the coatings is also affected. A selection of reviews has discussed the detail of metal deposition using ionic liquids (Abbott et al., 2008). Pollet et al., (2008), investigated the electrodeposition of copper from copper (II) chloride in aqueous potassium chloride and in mixtures of glycerol and choline chloride (2:1) DES on Pt electrodes, in the potential range for copper deposition and dissolution. In addition, the current density was increased using ultrasound within the two different solvents, when compared with the silent solution. The electrolytic deposition of copper and copper composites from a solution of the metal chloride salt has been studied in choline chloride based deep eutectic solvents. It was shown that the deposition kinetics and thermodynamics differ from the aqueous processes and that different complexes are formed.
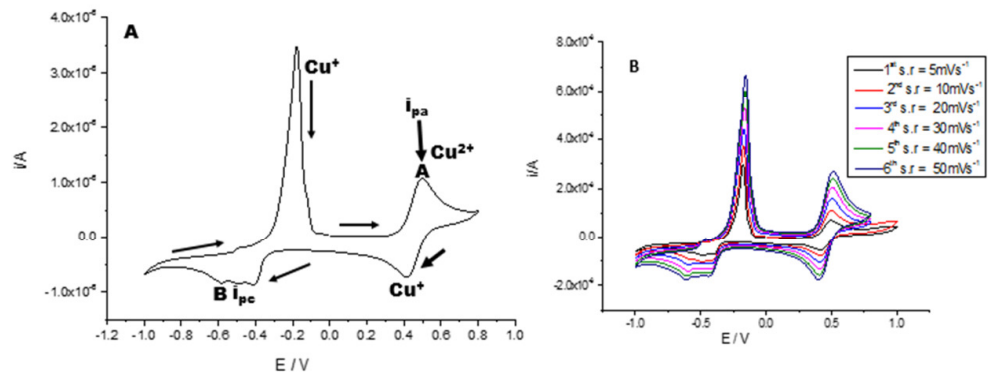

Fig.4: Showing Cyclic Voltammograms of $\mathrm{CuCl}_{2} .2 \mathrm{H}_{2} \mathrm{O}(0.05 \mathrm{M})$ in Ethaline at scan rate $10 \mathrm{mVs}^{-1}(\mathrm{~A})$, and different scan rate 5-50 $\mathrm{mVs}^{-1}(\mathrm{~B})$ using Pt disc versus Ag wire as reference electrode and Pt flag counter electrode at room temperature

Cyclic Voltammetry showed that the main species formed from the dissolution of $\mathrm{CuCl}_{2}$ in Deep Eutectic Solvent is $\left[\mathrm{Cu}^{2+}\right]$. Bulk electro deposition in DES results in different deposit morphologies to that encountered in aqueous solutions. The mechanism of copper nucleation was studied using chronoamperometry and it was shown that progressive nucleation leads to a bright nanostructured deposit. The current efficiency of copper deposition in this system is near $100 \%$ ( Abbott, et al., 2006)

Extraction and dissolution using deep eutectic solvents: A voltammetry study was carried out in ethaline based eutectic solvent containing chalcocite $\left(\mathrm{Cu}_{2} \mathrm{~S}\right)$ and chalcopyrite $\left(\mathrm{CuFeS}_{2}\right)$. The scan rate was maintained at $10 \mathrm{mV}$ at room temperature.

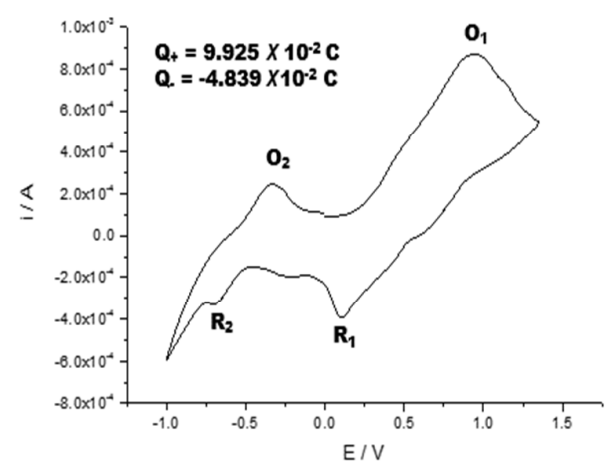

Fig. 5: Cyclic Voltammogram of $\mathrm{Cu}_{2} \mathrm{~S}$ in Ethaline at scan rate 10 $\mathrm{mVs}^{-1}$ using $\mathrm{Ag}$ wire as reference electrode and Pt flag counter electrode at room temperature 


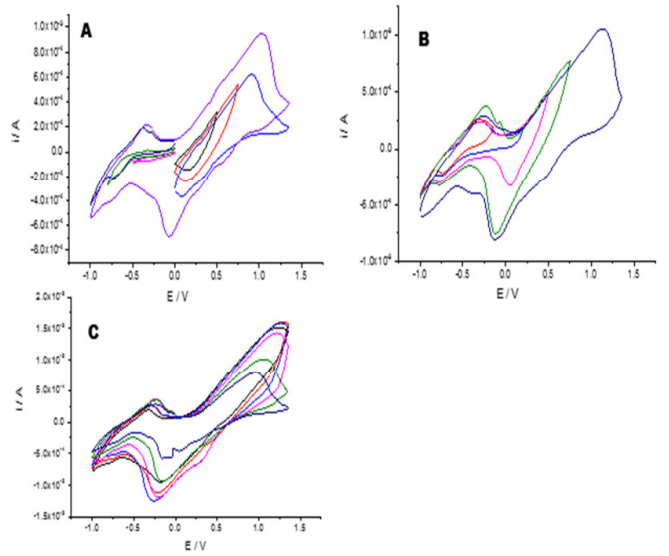

Fig. 6: Cyclic Voltammograms of $\mathrm{Cu}_{2} \mathrm{~S}$ at different oxidation limits(A), different reduction limits (B), and Different scan rates 5 $-50 \mathrm{mVs}^{-1}(\mathrm{C})$ in Ethaline using $\mathrm{Ag}$ wire as reference electrode and Pt flag counter electrode at room temperature.

The oxidative dissolution of chalcocite is a short circuited process involving both anodic and cathodic steps as follows;

At the Anode,

$$
\begin{aligned}
& \text { Step 1: } \mathrm{Cu}_{2} \mathrm{~S} \rightarrow \mathrm{CuS}+\mathrm{Cu}^{2+}+2 \mathrm{e}^{-} \ldots \ldots 1 \\
& \text { Step 2: } \mathrm{CuS} \rightarrow \mathrm{Cu}^{2+}+\mathrm{S}^{2-} \\
& \text { Overall Reaction: } \mathrm{Cu}_{2} \mathrm{~S} \rightarrow 2 \mathrm{Cu}^{2+}+\mathrm{S}^{2-}+2 \mathrm{e}^{-} \ldots 2 \\
& \mathrm{CuFeS}_{2} \rightarrow \mathrm{Cu}^{2+}+\mathrm{Fe}^{3+}+2 \mathrm{~S}^{0}+5 \mathrm{e}^{-} \ldots .3
\end{aligned}
$$

According to Ghosh, (2013), the first step involves the formation of a pseudo-covellite intermediate sulphide product which is subsequently oxidized to the elemental sulphur. The rate of the first step is very rapid, and controlled by the solid-state diffusion of copper in the sulphide lattice and the mass transport of chloride ions to the mineral surface. Therefore, it exhibits a low activation energy. The second step is much slower, controlled by the rate of charge transfer in the anodic decomposition process, and has an extremely high activation energy. The sulphide which is a semi-conductor acts as a conduit for electron transfer between the anodic and cathodic site in the mineral surface. It is expected that hydrogen ions from the glycol forms a solvation sphere around the chloride ions in the solution.

In Fig. 5, when the scan potential was initiated in the positive direction, an anodic peak, $\mathrm{O}_{1}$ at $1.35 \mathrm{~V}$, appeared. When the scan potential was inverted, two cathodic peaks, $R_{1}$ and $R_{2}$, were observed. These peaks can be associated with the reduction of the oxidation products formed in $\mathrm{O}_{1}$. comparison of these voltammograms, with those obtain by Dai et al., (2013), it is possible to establish that, when the scan potential is initiated in negative direction, a very small reduction process is observed, indicating that the chalcocite presents small quantities of chemical oxidation products on its surface formed during the chalcocite manipulation. At more negative potential, a reduction process associated with chalcocite is observed $\left(\mathrm{O}_{2}\right)$. The formation of covellite occurs by redox reaction when the scan potential is initiated in positive direction. The reduction processes associated to covellite formed during the direct scan potential, are related with the $R_{2}$ peak respectively. The peak $R_{2}$ diminish as the scan is more positive, indicating the total conversion of chalcocite to covellite. The peak potential associated to the peak $\mathrm{R}_{2}$ corresponds to the covellite reduction (equation $1 \& 2$ ) above. at $0.42 \mathrm{~V}$. The peak y1 corresponds to the partial oxidation of the mineral to mixed sulphides, as shown in the following reaction:

However, the intermediate product, and the sulphur form a passive electron-conducting layer on the mineral surface. Parker et al., (2014), referred to the product as a polysulphide, which has semi-conducting properties.

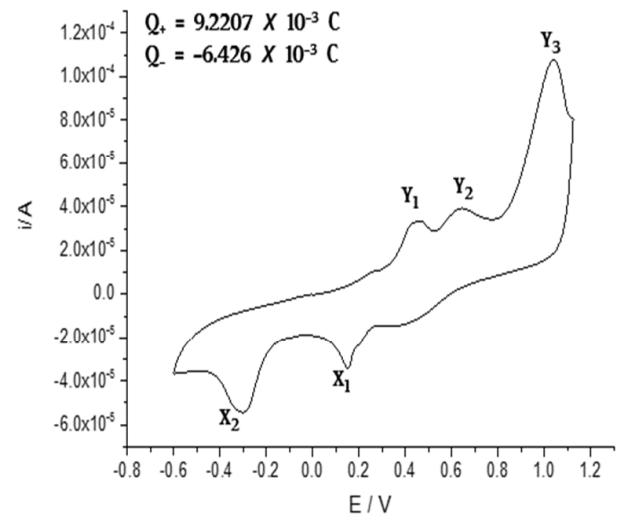

Fig.7: Cyclic Voltammogram of chalcopyrite $\mathrm{CuFeS}_{2}$ in Ethaline at scan rate $10 \mathrm{mVs}^{-1}$ using $\mathrm{Ag}$ wire as reference electrode and $\mathrm{Pt}$ flag counter electrode at room temperature 

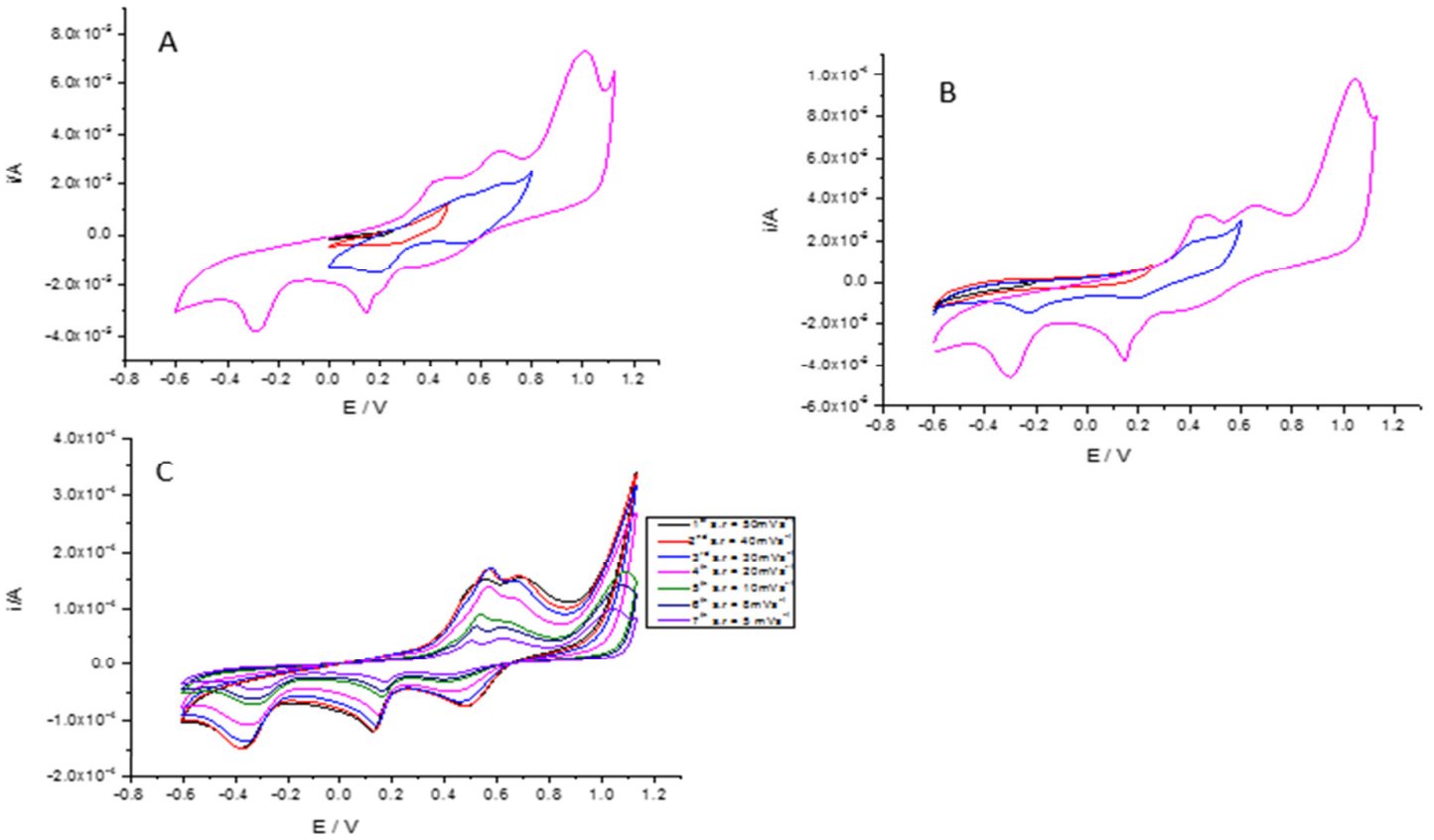

Fig.8: Cyclic Voltammograms of $\mathrm{CuFeS}_{2}$ at different oxidation limits(A), different reduction limits (B), and different scan rates (5-50 mVs ${ }^{1}$ ) in Ethaline using Ag wire as reference electrode and Pt flag counter electrode at room temperatur

An anodic peak y2 appears at $0.62 \mathrm{~V}$. The peak y2 reflects the oxidation of the intermediate (bornite) formed on the surface.

At more potential sweep, a well-defined anodic peak y3 appeared on the anodic scan at $1.0 \mathrm{~V}$. According to Pena-Pereira, and Namies (2013). This peak reflects the oxidation of the formed $\mathrm{Cu}_{2} \mathrm{~S}$ and $\mathrm{H}_{2} \mathrm{~S}$ to elemental sulphur respectively.

$$
\begin{aligned}
& \mathrm{Cu}_{2} \mathrm{~S} \rightarrow \mathrm{Cu}^{2+}+2 \mathrm{e}^{-} \\
& \mathrm{H}_{2} \mathrm{~S} \rightarrow \mathrm{S}^{\circ}+2 \mathrm{H}^{+}+2 \mathrm{e}^{-} \\
&
\end{aligned}
$$

On reversing the scan after peak $\mathrm{y} 3$ is formed, towards the cathodic direction a well-defined cathodic peak $\mathrm{X}_{1}$ was observed at $0.18 \mathrm{~V}$ which is been attributed to the formation of chalcocite by the reduction process.

On-going further on the cathodic direction, another well-defined cathodic peak $\mathrm{X}_{2}$ was observed at $-0.3 \mathrm{~V}$. The prewave peak $X_{1}$ reflects the reduction of the products produced at peak $\mathrm{y} 3$. The obvious difference in the areas under the anodic peak $\mathrm{y} 3$ and cathodic prewave peak $X_{1}$ indicate that the reaction is not completely reversible. This is likely due to dissolution of the product formed during the anodic sweep. This observation is consistent with the results of other investigators (Haerens et al., 2009b). The peak $\mathrm{X}_{2}$ which is attributed to the formation of chalcocite at more negative potentials than peak $\mathrm{X}_{1}$, and iron is completely removed from the chalcopyrite lattice, as shown in reaction
Conversely, in Ethaline, partial oxidation of the mineral (chalcopyrite) occur which gradually reduces

$$
\begin{aligned}
& 2 \mathrm{CuFeS}_{2}+6 \mathrm{H}^{+}+2 \mathrm{e}^{-} \rightarrow \mathrm{Cu}_{2} \mathrm{~S}+2 \mathrm{Fe}^{2+}+3 \mathrm{H}_{2} \mathrm{~S} \ldots .6 \\
& \mathrm{CuFeS}_{2} \rightarrow \mathrm{Cu}^{2+}+\mathrm{Fe}^{3+}+2 \mathrm{~S}^{0}+5 \mathrm{e}^{-} \\
& \mathrm{CuFeS}_{2}+\mathrm{Cu}^{2+}+5 \mathrm{e}^{-} \rightarrow 2 \mathrm{Cu}_{2} \mathrm{~S}+\mathrm{Fe}^{2+} \ldots . .6
\end{aligned}
$$

to chalcocite.

The main product of Chalcopyrite dissolution in Ethaline as evidenced from the enhanced $\mathrm{X}_{2}$ peak in Fig. 7 , is the formation of chalcocite $\left(\mathrm{Cu}_{2} \mathrm{~S}\right)$ which can thus, be leached more easily (Haerens et al., 2010).

Electroplating using deep eutectic solvents: Several electroplating processes have now been demonstrated in ionic liquids on the $10^{2}$ to $10^{3} \mathrm{~kg}$ scale. All these processes are based on eutectic-based ionic liquids, with the majority using deep eutectic solvents. Two in-depth reviews have been carried out into process scale up and contain information on process design and economics. Abbot et al., (2010), quantified the environmental impact of the choline chloride and ethylene glycol deep eutectic solvent system in electroplating applications. The main environmental impact was the heavy metals present in the rinse solutions. A variety of chlorinated products, including chloromethane, dichloromethane, and chloroform, were also found in small quantities, although chloride gas evolution was not observed at the anode. The liquids themselves were found to be non-harmful to the environment and readily biodegradable. The high viscosity resulted in enhanced mechanical loss through drag out, but rinse water could be easily 
treated with ion exchange to remove any metal residues (Abbot et al., 2010,). However, the presence of the chlorinated products was attributed to the existence of $\mathrm{Cl}^{3-}$ in the solution, which was observed photometrically. These chlorinated products could give rise to a large environmental impact, but formation of 2-methyl-1,3-dioxolane could be reduced by the addition of sacrificial agents, and the presence of chlorinated compounds could be reduced by the addition of water (Haerens et al., 2009b). The same group used pressure-driven membrane processes-nanofiltration, reverse osmosis, and pervaporation-for the recycling of deep eutectic solvents. Separation of water from a deep eutectic solvent could be achieved by evaporation, but the large energy consumption means that this technique is probably not feasible (Haerens et al., 2009a). One of the biggest technological breakthroughs for ionic liquids would be the electrodeposition of aluminium. The only successful process to date has been the SIGNAL process, which has been operated under commercial conditions but has proven difficult to operate due to the pyrophoric nature of triethylaluminium and the solvent, toluene.

Abbott et al., (2010), succeeded in scaling up aluminium plating process to a 20 -liter scale by using 1-ethyl-3-methyl-imidazoliumchloride/ $\mathrm{AlCl}_{3}$ under a nitrogen atmosphere. It was possible to deposit 10$\mu \mathrm{m}$-thick pure-aluminium layers on a range of substrates, including steel and copper. The same group showed that under potential deposition is an important factor in the growth method and that the anodic reaction is as important as the cathodic reaction for controlling deposit morphology (Abbott et al., 2010). Incompatibility with materials required for the plating rig meant that corrosion particularly that of plastic components was a long-term issue. Furthermore, without rigorously dry conditions, it was not possible to operate the plant for longer than1month without significant degradation of the ionic liquid resulting from water adsorption. A similar study recently showed that eutectics based on $\mathrm{AlCl}_{3}$ and amides produce a less water sensitive system that could be operated under an ambient atmosphere following minor modification (Abood et al., 2011). Although practical samples have been electroplated with aluminium from this system, its present operation lifetime is also less than 1 month. As a result, it has been possible to use a variety of chloroaluminate ionic liquids to deposit aluminium onto various substrates by various electrochemical methods (Haerens et al., 2009a). However, many other elements can be deposited easily, such as silver, copper and palladium. Furthermore, technically important alloys such as $\mathrm{Al} / \mathrm{Mg}, \mathrm{Al} / \mathrm{Cr}$ and others can be made by electrochemical means. Addition of organic solvents such as benzene or toluene has shown that bright finishes can be obtained after deposition (Liao et al., 1997). The miscibility of the chloroaluminate based ionic liquids with organic solvents such as toluene and benzene means that the ionic liquid can be cleaned away from the sample after deposition has taken place. The scope for electrochemically depositing metals successfully is large with the use of ionic liquids. Metals such as Ag, $\mathrm{Cu}, \mathrm{Pd}, \mathrm{In}, \mathrm{Sb}, \mathrm{Te}, \mathrm{Cd}$ and others have been deposited (Smith et al., 2010). Today about 300 different ionic liquids with different qualities are commercially available from a wide range of companies.

Anodic Reactions: Anodic reactions are commonly ignored in ionometallurgical electroplating. Although these reactions may be insignificant for most research experiments on a laboratory scale, this area needs to be urgently addressed for industrial applications. In aqueous systems, the anodic reaction is usually the breakdown of the solvent, and because the solvent is present in approximately100-fold excess to the metal species, it is usually not rate limiting. In ionic liquids, the decomposition of either the anionic or cationic species is rarely an option, and a soluble anode must usually be used for large-scale plating (Endres et al., 2008). The advantage of using ionic liquids is that almost all metals are anodically soluble, provided that a suitable ligand is present to solubilize the metal. One of the issues is that, due to the high viscosity of ionic liquids, the ligand mobility and concentration often make the anodic reaction rate limiting (Abbott et al., 2010).

This was demonstrated for the first time using a chloro-aluminate ionic liquid. For the electrodeposition of aluminium from Lewis acidic imidazolium chloride: $\mathrm{AlCl}_{3}$ eutectic mixtures, deposit morphology was limited by the anodic reaction (Abood et al., 2011). Pre -treatment of the aluminium anode was important, as the presence of oxide on the anode surface decreased the rate of the cathodic reaction. However, the dissolution of aluminium from the anode was limited by the diffusion of suitable ligands to the anode surface. As $\mathrm{Al}^{3+}$ leaves the electrode, the only species available to solvate it is $\mathrm{AlCl}_{4}^{-}$(Abood et al., 2011).

$$
\mathrm{Al}^{3+}+7 \mathrm{AlCl}_{4}{ }^{-} \leftrightarrow 4 \mathrm{Al}_{2} \mathrm{Cl}_{7}{ }^{-} \ldots .9
$$

This will understandably be a slow process. Anodic reactions involving electro-oxidation of the ionic liquid are clearly undesirable, and so a method of using either a well-soluble sacrificial species with high mobility or an electrocatalyst would be advantageous for speeding up the anodic reaction and hence, for making the cathodic deposition process rate limiting (Abbott et al., 2007).

Conclusion: Because ionic liquids have a much larger potential window than organic solvents, certain metals can be electrochemically deposited that are 
otherwise inaccessible to organic solvents. As an analytical method, electrochemical techniques have been widely penetrated into various scientific areas of mineral-related analysis. Electrochemical dissolution process shows promises as a viable route for the electro-hydrometallurgical processing of metals. Anodic reactions in ionometallurgical electroplating needs to be urgently addressed for industrial applications.

\section{REFERENCES}

Abbott, AP; Green Capper, DL; Davies, RK; Vasuki, T (2003). "Novel Solvent properties of chlorine chloride/urea mixture" Chem.Comm: 47: 70-71.

Abbott, AP; Capper, G; McKenzie, KJ; Ryder, KS (2006). Electropolishing of stainless steels in a choline chloride based ionic liquid: an electrochemical study with surface characterisation using SEM and atomic force microscopy. Chem. Phys: 8: 4214-21.

Abbott, AP; Barron, J; Karl, SR; Wilson, D (2007a). "Eutectic-Based Ionic liquids with metalcontaining Anions and cations". Chem. Phys: 13: 6495-6501.

Abbott, AP; Katy, JM; Karl, SR (2007b). "Electropolishing and Electroplating of metals using ionic liquids based on choline chloride". America Chemical Society symposium series: 126; 186-197.

Abbott, AP; Ryder, KS; Koenig, U; (2008). Electrodeposition of metals using Eutectic based ionic liquids. Trans. Inst. Met. Finish. 86:196 204.

Abbott, AP; K. El Ttaib, GF; McKenzie, KJ; Ryder, KS; (2009). Electrodeposition of copper composites from deep eutectic solvents based on choline chloride,

Chem. Phys: 11: 4269 - 4276.

Abbott, AP; Qiu, F; Abood, HM; Ali, MR; Ryder, KS (2010). Double layer, diluent And Anode effects upon the electrodeposition of aluminium from chloroaluminate based ionic liquids. J.Phys. Chem. 12:1862-1872.

Abood, HMA; Abbott, AP; Ballantyne, AD; Ryder, KS (2011). Do all ionic liquids need organic cations? Characterization of $\left[\mathrm{AlCl}_{2}{ }^{-} \mathrm{nAmide}\right]^{+}$ $\mathrm{AlCl}_{4}{ }^{-}$and comparison with imidazolium based systems. Chem. Commun. 47: 3523-25.

Bagh, FK; Shahbaz, FS; Mjalli, IM; Hashi, M (2013). Electrical conductivity of ammonium and phosphonium based deep Eutectic solvents:
Measurements and artificial intelligence-based prediction. Fluid Phase Equilibria. 56: 30 - 37.

Chan,CP; LamH, LKK; Surya,C; (2010).Growth of copper tin sulfide nano-rods by electro deposition using anodized aluminium as growth mask. Nonlinear Opt. Phys. Mater. 18:599-603.

Dai, GJ; Witkamp, R; Verpoorte, YH; Choi, V (2013). Natural Deep Eutectic Solvents as a New Extraction Media for Phenolic Metabolites in Carthamus tinctures L. Analytical Chemistry, 85: (13), 6272-6278.

Endres, F; El Abedin, SZ; Saad, AY; Moustafa, EM; Borissenko, N (2008) The electro deposition of titanium in ionic liquids. Phys. Chem. Chem. Phys. 10: 2189 -2199.

Free, ML (2003). Hydrometallurgy fundamentals and applications, John Wiley \& Sons, 56: 145 - 155.

Ghosh, S (2013). Electrodeposition of $\mathrm{Cu}, \mathrm{Sn}$ and $\mathrm{Cu}-$ Sn Alloy from Choline Chloride Ionic Liquid, (Ph.D. Thesis).

Haerens, K; Matthijs, E; Binnemans, K; Van der Bruggen, B (2009a). Electrochemical decomposition of choline chloride based ionic liquid analogues. Green Chem. 11:1357-65.

Haerens, K; Van DS; Matthijs, E; Van der Bruggen, B (2010). Challenges for recycling ionic liquids by using pressure driven membrane processes. Green Chem. 12: 2182-88.

Haerens, K; Matthijs, E; Chmielarz, A; VanderBruggen, B (2009b). The use of ionic liquids based on choline chloride for metal deposition: A green alternative, J. Environ. Manag. 90:3245-3252.

Jurcik, V; Wilhelm, R (2005). An imidazolinium salt as ionic liquid for medium and strong bases. Green Chem. 7: 844-848.

Kareem, MA; Mjalli, M; Hashim, A; AlNashef, IM (2010). Phosphonium- Based Ionic Liquids Analogues and Their Physical Properties. Journal of Chemical \& Engineering Data. 55(11): 4632-4637.

Kautek, W; Birkle S (1989). Aluminumelectrocrystallization from metal- Organic electrolytes. Electrochim. Acta. 34:1213-1318.

Kurig, H; Vestli, M; Tonurist, K; Janes, A; Lust, E (2012). Influence of Room temperature ionic liquid anion chemical composition and electrical 
charge delocalization on the supercapacitor properties. J. Electrochem.

Society. 159: A944-51.

Liao, Q; Pitner WR; Steward, G; Hussey, CL (1997). Electrodeposition of aluminium from the aluminumchloride-1-methyl-3-ethylimidazolium chloride room temperature molten salt + benzene. J. Electrochem. Society. 144: 936-943.

Pena-Pereira, F; Namies, J (2013). Int. J. Mineral processing. 10: 10002.

Perre, E; Nyholm, L; Gustafsson, T; Taberna, PL; Simon, P Edstroem, K (2008).

Direct electrodeposition of aluminium nanorods. Electrochem. Commun. 10:1467-70.
Qinghua, Z; Karine, Vigier, DO; Se'bastien, R; Franc O (2012). Deep eutectic solvents, syntheses, properties and applications. Int. J. Electrochem.Sci 41: 7108-7146.

Sato, T; Maruo, T; Marukane, S; Takagi, K (2004). Ionic liquids containing carbonate solvent as electrolytes for lithium ion cells. J. Power Sources. 138: 253-261.

Smith, EL; Abbott, AP; Griffin,J; Harris, RC; Connor, C; Ryder,KS (2010). Pilot trials of silver deposition using choline chloride based ionic liquids. Circuit World 36: 3 - 9.

Zhao, F; Zeng, B (2010). Electrodeposition of PtCo alloy nanoparticles on inclusion complex film of functionalized cyclodextrin ionic liquid and their application in glucosesensing. Electrochem.Commun. 12:168 -171. 